\title{
INDIAN HISTORY AND CULTURE IN THE VOLGOGRAD ORIENTAL STUDIES
}

\author{
Vasiliy V. Tarakanov \\ Volgograd State University, Volgograd, Russian Federation \\ Irina K. Cheremushnikova \\ Volgograd State Medical University, Volgograd, Russian Federation
}

\author{
Aleksandr A. Kiselev \\ Volgograd City Administration, Volgograd, Russian Federation
}

\begin{abstract}
The article is devoted to the study of Indian history and culture in Volgograd in the late $20^{\text {th }}-$ early $21^{\text {th }}$ century under the guidance of famous Russian orientalists Arkady Ya. Serebryany and Evgeny L. Besprozvannyh. The authors write about their organizational, scientific and pedagogical activity. Scientific works of Volgograd orientalists, who are pupils of Arkady Ya. Serebryany and Evgeny L. Besprozvannyh, are noted.

Key words: India, Indology, Orientalism, Volgograd, Volgograd State University, Volgograd State Social Pedagogical University.

Citation. Tarakanov V.V., Cheremushnikova I.K., Kiselev A.A. Indian History and Culture in the Volgograd Oriental Studies. Vestnik Volgogradskogo gosudarstvennogo universiteta. Serija 4, Istorija. Regionovedenie. Mezhdunarodnye otnoshenija [Science Journal of Volgograd State University. History. Area Studies. International Relations], 2017, vol. 22, no. 3, pp. 194-200. (in Russian). - DOI: https://doi.org/10.15688/jvolsu4.2017.3.18
\end{abstract}

УДК 930(470.45):001

Дата поступления статьи: 27.06.2017

ББК $63.1(2) 64$ Дата принятия статьи: 20.07.2017

ИСТОРИЯ И КУЛЬТУРА ИНДИИ В ИССЛЕДОВАНИЯХ ВОЛГОГРАДСКИХ ВОСТОКОВЕДОВ

\author{
Василий Валерьевич Тараканов \\ Волгоградский государственный университет, г. Волгоград, Российская Федерация
}

Ирина Кабдрахимовна Черемушникова

Волгоградский государственный медицинский университет, г. Волгоград, Российская Федерация

Александр Александрович Киселев

Администрация Волгограда, г. Волгоград, Российская Федерация

Аннотация. Статья посвящена исследованию истории и культуры Индии в Волгограде на рубеже XX-XXI вв.
под руководством известных отечественных востоковедов А.Я. Серебряного и Е.Л. Беспрозванных. Дана характери-
стика их организаторской и научно-педагогической деятельности. Отмечены научные труды их учеников.
Ключевые слова: Индия, индология, востоковедение, Волгоград, Волгоградский государственный уни-
верситет, Волгоградский государственный социально-педагогический университет.
Цитирование. Тараканов В. В., Черемушникова И. К., Киселев А. А. История и культура Индии в иссле-
дованиях волгоградских востоковедов // Вестник Волгоградского государственного университета. Серия 4 ,
История. Регионоведение. Международные отношения. - 2017. - Т. 22, № 3. - С. 194-200. - DOI: https://
doi.org/10.15688/jvolsu4.2017.3.18.
} 
В 2017 г. Российская Федерация и Республика Индия отмечают 70-летний юбилей дипломатических отношений. Это важное событие не могло остаться незамеченным в Волгограде, где сложилась целая научная школа индологии.

Одним из старейших и самых опытных волгоградских исследователей восточноазиатской цивилизации является кандидат исторических наук, доцент кафедры всеобщей истории Волгоградского государственного социально-педагогического университета Аркадий Яковлевич Серебряный. Он начал свою исследовательскую деятельность в 1968 году. Его обращение к индийской тематике естественным образом было связано с изучением проблем буддизма, которые являются центральными в его научном творчестве. Многие аспекты индийской культуры рассмотрены им в контексте общей концепции отечественного востоковедения.

Так, вопрос о становлении русского востоковедения до сих пор, по мению А.Я. Серебряного, остается дискуссионным. Причиной такого положения дел является разделение востоковедения, уже в самый момент его возникновения, на практическое, которое интересовало дипломатов, торговцев, миссионеров и других представителей государственных и церковных институтов; и научное, которое касалось «умозрительных» тем, не имеющих явного прикладного применения. Он прослеживает становление российского востоковедения [15] от создания первых научных коллективов востоковедческих центров, создание которых приходится на начало XVIII в. (первым научным коллективом можно считать Российскую духовную миссию, созданную по Указу Петра I в 1712 г.), и до появления научных университетских кафедр, специалисты которых внесли огромный вклад в изучение стран Востока и сделали востоковедение полноценной отраслью исторической науки. Подлинным центром индологии становится Восточный факультет Санкт-Петербургского университета. Кроме университетов и духовных учреждений значительный вклад внесли Министерство иностранных дел, в котором имелся Азиатский департамент и Военное ведомство.

А.Я. Серебряный в своей работе описывает интереснейший феномен в становлении российского востоковедения - постепенный «поворот от лингвистики к истории». Первоначально деятельность «востоковедных» кафедр носила по преимуществу филологический и прикладной характер, они выпускали переводчиков и преподавателей восточных языков, большинство из которых либо оставалось в сфере чистой филологии, либо служило в Министерстве иностранных дел. Однако постепенно часть специалистов становилась историками, поскольку простой перевод без объяснения был часто непонятен, переводчики писали сопроводительные справки, пытались объяснить отсутствующие в российских реалиях понятия и дать комментарии к ним. Это была уже частично и историческая работа. Со временем объяснение и историческая трактовка стали главной частью работы практикующих переводчиков.

Обращаясь к деятельности наиболее видных ученых, начавших свою научную карьеру в качестве переводчиков, но впоследствии ставших исследователями истории и культуры Восточной Азии (это И.К. Рассохин, А.Л. Леонтьев, П.И. Кафаров и многие другие), А.Я. Серебряный показывает, как в их работах и творчестве совершился переход от переводческого к новому этапу, который можно назвать подлинно исследовательским. В это время в востоковедении наметился поворот интересов от проблем исключительно религиозного и философского характера к политико-юридическим, экономическим, статистикодемографическим, что способствовало более полному пониманию истории и культуры стран Востока. Так, творчество Н.Я. Бичурина, работы которого признаны вершиной российского востоковедения, было результатом взаимодействия двух начал: университетского образования и его «полевой работы» в качестве главы Духовной миссии. Практически все русские духовные миссии Индии и Китая становились научными центрами, где собирались и переводились источники, составлялись словари и учебники, выполнялись дипломатические и политические обязанности. Интересно, что в работах российских востоковедов появляются темы, которые можно считать предвестниками исследований в области столь актуальной сегодня культуры повседневности. Среди них: «Ежедневные упражнения китайс- 
кого императора» или «Взгляд на просвещение в Китае», рассказывающие россиянам и европейцам о повседневной жизни и экзаменационной системе Востока.

Интерес к Индии, ее истории, культуре, существовал в России всегда, и в последние десятилетия наблюдается восстановление прерванной традиции изучения и перевода на русский язык литературных текстов и документов. Любопытно, что образованная российская публика уже в XVIII-XIX вв. имела возможность читать труды крупнейших мировых ученых-востоковедов, изданные на иностранных языках. Текст Бхагаватгиты был опубликован в России в 1788 г., а вскоре после был сделан перевод пьесы самого знаменитого писателя и поэта Древней Индии Калидасы «Шакунтала». Комментарий и предисловие были написаны самим Н.M. Карамзиным, который дал высочайшую оценку произведению. Интерес к Индии был столь высоким, что статьи о ней печатались в таких популярнейших изданиях, как «Московские ведомости», «Вестник Европы», «Отечественные записки» и «Библиотека для чтения». Эти статьи имели популярность и в таких российских журналах, как «Московитянин», «Московский телеграф», «Сын Отечества».

Обращение к периодическим изданиям позволило автору сделать замечательный вывод о том, что индийская проблематика, которой интересовалась русская общественная мысль, была в целом та же, что и в европейских странах, а временной зазор между знаниями об Индии в Западной Европе и России в XIX в. был минимальным или практически отсутствовал.

Концептуальным подходом можно считать то, что А.Я. Серебряный рассматривает развитие отечественного востоковедения на фоне основных тенденций всемирной истории, в которой в то время господствовал европоцентризм. Европейский путь развития представлялся как единственно верный, а все остальные варианты культуры - как «нечто вроде природного брака». Российские востоковеды, в частности И.П. Минаев, одними из первых выступили против господствующей концепции Гегеля - Монтескье, согласно которой индийское общество было неподвижным и влачило «растительное» существование на протя- жении многих тысячелетий своей истории. Уже в своей инаугурационной речи при вступлении в профессорскую должность И.П. Минаев заявил, что подобная точка зрения «далеко не правдива» [13]. Кроме того, он как один из фундаментальных авторов по истории буддизма, и как автор каталога палийских рукописей (пали - язык, на котором говорил Будда и были написаны первые тексты буддийского канона) поставил под сомнение степень древности так называемого «буддийского канона» и выдвинул тезис о том, что канон является компиляцией многих предыдущих текстов и результатом длительной редакторской обработки, а вовсе не цельным произведением какого-то одного периода. Несомненно, И.П. Минаеву нужна большая эрудиция, безупречное знание языков, включая пали, а также научная смелость, чтобы заявить о том, что «палийский канон» написан не сразу после смерти Будды, как принято считать, а лишь спустя 400 лет.

Тормозило изучение документов Древней Индии незнание санскрита, языка большинства индийских текстов. Индийские языки начинают преподаваться в Московском и Казанском университетах. В этой связи следует упомянуть Герасима Лебедева, музыканта и театрального деятеля, оказавшегося в Индии в 40-х гг. XIX в. и подготовившего грамматику бенгальского языка, а затем и санскрита.

В 2004-2006 гг. А.Я. Серебряный на кафедре всеобщей истории ВГСПУ подготовил к изданию сразу два учебных пособия «Индуизм» и «Религии Индии» [9; 14], в которых дается очерк возникновения и содержания двух самых известных религий Индии - индуизма и буддизма. Структура работы об индуизме позволяет познакомиться с источниками для его изучения, проследить основные этапы его формирования, знакомит со школами и течениями, описывает феномен храмовой жизни и жречества, знакомит с обрядами и праздниками. Оба сборника снабжены словарями понятий и категорий индуизма, которые доступно раскрывают содержание основных культурных феноменов. Концепция работы об индуизме, который допускает внутри себя множество разных, порой противоположных философских и религиоз- 
ных течений, построена автором таким образом, что позволяет понимать индуизм не только как религию, но как мировоззренческую концепцию, которая регулирует социальную жизнь, ее институты, быт и повседневность, обычаи и традиции.

Большой вклад в развитие индологии внесла научная школа доктора исторических наук, профессора Евгения Леонидовича Беспрозванных (1945-2014), сложившаяся в Волгоградском государственном университете. Под его руководством уже в конце 1980-х начале 1990-х гг. было подготовлено и защищено много дипломных работ и работ молодых исследователей, которые касались различных аспектов индологии, в том числе русско-индийских отношений на разных исторических этапах. В частности, на широком фактологическом материале были исследованы русскоиндийские связи, представленные астраханской колонией индийских купцов, которая существовала на протяжении XVII-XIX веков. Изучение более 530 документов (среди которых документы таможни, описи товаров, оплата пошлин, обращения купцов к местным властям и др.), собранных в архивах Москвы, Ленинграда, Астрахани и Оренбурга и изданных в 1958 и 1965 гг. академическими сборниками АН, показало, что русско-индийские связи не были просто незначительными эпизодами, но, напротив, носили характер тесных и постоянных контактов.

Нужно отметить, что Е.Л. Беспрозванных в 1990-е гг. было многое сделано для популяризации упомянутого Герасима Лебедева, который был крупнейшим ученым-индологом своего времени. В начале XIX в. не было более крупного знатока истории, культуры и языков Индии, чем он, а его труды были известны и оценены за границей. Долгое время его имя было почти забыто. Сегодня о Г.С. Лебедеве много пишут, издаются книги в Ярославле и Петербурге, его уникальные работы изучаются снова и снова, сам он часто становится центральной фигурой российских и международных конференций, в Астрахани восстановлено «индийское подворье», где некогда был центр индийской купеческой колонии. И вклад волгоградской школы здесь очевиден.

Научные интересы Е.Л. Беспрозванных были очень разнообразными. Кроме Индии он исследовал историю Центральной Азии и Дальнего Востока, являлся крупным специалистом по Китаю и Тибету. Ключевой темой его исследований оставалась политика Китая в Азии в Новое время [1-5]. Впоследствии индийская тематика разрабатывалась в трудах учеников Е.Л. Беспрозванных. Так, Е.Г. Ефимов посвятил свое диссертационное исследование политике британской Ост-Индской компании в Тибете во второй половине XVIII века [6]. Ему удалось доказать, что планы руководства компании по развитию торговых связей между Британской Индией и Китаем через посредничество Тибета оказались неосуществимыми изза политической реформы 1784 г. в Великобритании. Ост-Индская компания была поставлена под полный контроль государства, и в последней четверти XVIII в. ее действия в Азии определялись уже не торговыми, а внешнеполитическими интересами метрополии.

Взаимоотношениям Лондона и британской Ост-Индской компании в XVII-XVIII вв. уделено значительное внимание в исследованиях А.А. Киселева [7; 8]. Автор сконцентрировал свое внимание на деятельности в британских органах власти так называемого «остиндского лобби», которое оказывало значительное влияние на формирование политики метрополии к Индии и всему азиатскому региону. Также, опираясь на экономическую статистику, ему удалось доказать, что описываемого в отечественной историографии британского «поворота на Восток» в конце XVIII в. на самом деле не произошло.

Важный вклад в востоковедение внесла В.А. Лукьянова. Ее диссертационное исследование посвящено политике Великобритании в Тибете в первой половине XX в. [10], однако центральной концепцией всей работы стала значимость «индийского» фактора в отношениях Великобритании с ведущими державами, определявшими расстановку сил в Центральной Азии - Российской империей/СССР и Китаем.

Актуальным проблемам современной Индии посвящены диссертационные исследования последних учеников Е.Л. Беспрозванных - молодых историков А.С. Михалева и А.И. Харинина.

А.С. Михалев представил глубокий анализ конфликта радикального движения накса- 
лизма и индийского государства. Опираясь на маоистские постулаты середины XX в., современные наксалиты используют террористические методы в своей борьбе против правительства Индии. А.С. Михалеву удалось выявить причины развития наксализма в наши дни, которые кроются в застойности индийского общества, нерешенности застарелых социальных проблем. Тем не менее автор пришел к выводу, что наксализм обречен на провал из-за своей устаревшей идеологии и террористических методов борьбы. Наиболее эффективным способом борьбы с маоистским радикализмом исследователь считает улучшение социально-экономической ситуации в Индии [11; 12].

Уникальными стали научные труды А.И. Харинина. Автор впервые в отечественной историографии исследовал проблему «неприкасаемых» этнокастовых сообществ, используя методы исторической социологии. Он смог доказать, что модернизация размывает кастовые рамки традиционного индийского общества. В начале XXI в. оно успешно адаптируется к современным реалиям, в то же время, сохраняя свои сущностные, культурно обусловленные черты. Архаические представления о «ритуальной чистоте» сменяются понятиями рентабельности производства, урбанизированности, интеллектуального развития. Учитывая, что современная Индия очень активно развивается и экономически, и политически, А.И. Харинин прогнозирует большие перемены для общества этой страны [16-18].

В 2014 г. после продолжительной болезни Евгений Леонидович Беспрозванных скончался. Его смерть стала невосполнимой утратой для российских востоковедов, волгоградских коллег-историков и, прежде всего, учеников. Однако он успел заложить в Волгограде фундамент серьезной научной школы.

Таким образом, благодаря кандидату исторических наук, доценту А.Я. Серебряному и доктору исторических наук, профессору Е.Л. Беспрозванных в Волгограде сформировалось направление научных исследований по востоковедению, индологии, к сожалению, угасающее в современной российской науке. Активное укрепление широких международных связей между Российской Федерацией и Индией, другими странами Востока, в XXI в. дает надежду на то, что труды специалистоввостоковедов будут широко востребованы со стороны государственных структур, бизнеса, науки и общества, а школа волгоградской индологии получит дальнейшее развитие.

\section{СПИСОК ЛИТЕРАТУРЫ}

1. Беспрозванных, Е. Л. Буддизм и политика: лидеры Тибета в XVII-XVIII вв. / Е. Л. Беспрозванных. - Волгоград : Изд-во Волгогр. гос. ун-та, 1998. $204 \mathrm{c}$.

2. Беспрозванных, Е. Л. Калмыцко-китайские отношения в XVIII веке / Е. Л. Беспрозванных. Волгоград : Изд-во Волгогр. гос. ун-та, 2008. - 370 с.

3. Беспрозванных, Е. Л. Лидеры Тибета и их роль в тибето-китайских отношениях XVII-XVIII вв. / Е. Л. Беспрозванных. - Волгоград : Изд-во Волгогр. гос. ун-та, 2001. - 354 с.

4. Беспрозванных, Е. Л. Приамурье в системе русско-китайских отношений (XVII - середина XIX в.) / Е. Л. Беспрозванных. - М. : Наука, 1983. $206 \mathrm{c}$.

5. Беспрозванных, Е. Л. Экспансионистская политика династии Цин в Центральной Азии (XVIIXVIII вв.) : учеб. пособие / Е. Л. Беспрозванных. Саратов : Изд-во Сарат. гос. ун-та, 1990. - 74 с.

6. Ефимов, Е. Г. Политика Ост-Индской компании в Тибете во второй половине XVIII в. : дис. ... канд. ист. наук / Ефимов Евгений Геннадиевич. Волгоград, 2005. - 207 c.

7. Киселев, А. А. Великобритания и английская Ост-Индская компания во второй половине XVIII века / А. А. Киселев // Вестник Волгоградского государственного университетата. Серия 4, История. Регионоведение. Международные отношения. -2008 . - № 1 (13). - С. 73-81.

8. Киселев, А. А. Рождение империи. Британское государство и колониализм в XVII-XVIII вв. / А. А. Киселев. - Волгоград : Изд-во Волгогр. гос. ун-та, 2012. $-332 \mathrm{c.}$

9. Лопанцев, Ю. М. Религии Индии / Ю. М. Лопанцев, А. Я. Серебряный. - Волгоград : Перемена, 2006. $-192 \mathrm{c}$.

10. Лукьянова, В. А. Политика Великобритании в Тибете: 1903-1948 гг. : дис. ... канд. ист. наук / Лукьянова Виолетта Александровна. - Волгоград, 2005. $-212 \mathrm{c}$.

11. Михалев, А. С. Движение «Сальва Джудум» в Индии в 2005-2008 годы / А. С. Михалев // Вестник Волгоградского государственного университетата. Серия 4, История. Регионоведение. Международные отношения. -2010 . - № 1 (17). - С. 139-144.

12. Михалев, А. С. Наксалиты и борьба с ними правительства Индии в первом десятилетии 
XXI века : дис. ... канд. ист. наук / Михалев Александр Сергеевич. - Волгоград, 2010. - 260 с.

13. Серебряный, А. Я. И. П. Минаев как историк буддизма / А. Я. Серебряный // Историческое знание в системе политики и культуры : сб. ст. Волгоград : Перемена, 2005. - С. 78-83.

14. Серебряный, А. Я. Индуизм / А. Я. Серебряный. - Волгоград : Перемена, 2004. - 80 с.

15. Серебряный, А. Я. Становление русского востоковедения / А. Я. Серебряный // Проблемы новой и новейшей истории и опыт современности : сб. ст. Волгоград : Перемена, 2009.-С. 180-188.

16. Харинин, А. И. «Неприкасаемые» касты Уттар-Прадеша / А. И. Харинин // Вестник Волгоградского государственного университетата. Серия 4, История. Регионоведение. Международные отношения. - 2015. - № 1 (31). - С. 32-41.

17. Харинин, А. И. «Неприкасаемые» этнокастовые сообщества Индии: модернизация социокультурных традиций : дис. ... канд. ист. наук / Харинин Артем Игоревич. - Волгоград, 2017. - 249 с.

18. Харинин, А. И. Субъект глобализации: от транснационального агента к субъективному фактору планетарной интеграции / А. И. Харинин // Вестник Волгоградского государственного университетата. Серия 7, Философия, социология и социальные технологии. - 2010. -№ 2. - С. 142-147.

\section{REFERENCES}

1. Besprozvannykh E.L. Buddizm i politika: lidery Tibeta $v$ XVII-XVIII vv. [The Buddhism and Politics: the Leaders of Tibet in the $17^{\text {th }}-18^{\text {th }}$ Centuries]. Volgograd, Izd-vo VolGU, 1998. 204 p.

2. Besprozvannykh E.L. Kalmytsko-kitayskie otnosheniya $v$ XVIII veke [The Kalmyk-Chinese Relations in the $18^{\text {th }}$ Century]. Volgograd, Volgograd, Izd-vo VolGU, 2008. 370 p.

3. Besprozvannykh E.L. Lidery Tibeta i ikh rol v tibeto-kitayskikh otnosheniyakh XVII-XVIII vv. [The Leaders of Tibet and Their Role in the Tibetan-Chinese Relations of the $17^{\text {th }}-18^{\text {th }}$ Centuries]. Volgograd, Izdvo VolGU, 2001. 354 p.

4. Besprozvannykh E.L. Priamurye v sisteme russko-kitayskikh otnosheniy (XVII-seredina XIX v.) [Priamurye in the System of the Russian-Chinese Relations $\left(17^{\text {th }}-\right.$ mid $19^{\text {th }}$ Century) $]$. Moscow, Nauka Publ., 1983. 206 p.

5. Besprozvannykh E.L. Ekspansionistskaya politika dinastii Tsinv Tsentralnoy Azii (XVII-XVIII veka): uchebnoe posobie [The Expansionist Policy of the Qing Dynasty in Central Asia (17 $17^{\text {th }}-18^{\text {th }}$ Centuries): Manual]. Saratov, Izd-vo Saratovskogo gos. un-ta, 1990. 74 p.

6. Efimov E.G. Politika Ost-Indskoy kompanii $v$ Tibete vo vtoroy polovine XVIII v.: dis. ... kand. ist. nauk [The Policy of the East India Company in Tibet during the Second Half of the $18^{\text {th }}$ Century. Cand. hist. sci. diss.]. Volgograd, 2005. 207 p.

7. Kiselev A.A. Velikobritaniya i angliyskaya Ost-Indskaya kompaniya vo vtoroy polovine XVIII veka [Great Britain and British East India Company in the Second Half of the $18^{\text {th }}$ Century]. Vestnik Volgogradskogo gosudarstvennogo universiteta. Seriya 4, Istoriya. Regionovedenie. Mezhdunarodnye otnosheniya [Science Journal of Volgograd State University. History. Area Studies. International Relations], 2008, no. 1 (13), pp. 73-81.

8. Kiselev A.A. Rozhdenie imperii. Britanskoe gosudarstvo i kolonializm v XVII-XVIII vv. [The Birth of Empire. British State and Colonialism in the $17^{\text {th }}$ $18^{\text {th }}$ Centuries]. Volgograd, Izd-vo VolGU, 2012. 332 p.

9. Lopantsev Yu.M., Serebryany A.Ya. Religii Indii [The Religions of India]. Volgograd, Peremena Publ., 2006. 192 p.

10. Lukiyanova V.A. Politika Velikobritanii v Tibete: 1903-1948 gg.: dis. ... kand. ist. nauk [The Policy of Great Britain in Tibet, 1903-1948. Cand. hist. sci. diss.]. Volgograd, 2005. 212 p.

11. Mikhalev A.S. Dvizhenie «Salva Dzhudum» v Indii v 2005-2008 gody [The 'Salva Judum' Movement in 2005-2008]. Vestnik Volgogradskogo gosudarstvennogo universiteta. Seriya 4, Istoriya. Regionovedenie. Mezhdunarodnye otnosheniya [Science Journal of Volgograd State University. History. Area Studies. International Relations], 2010, no. 1 (17), pp. 139-144.

12. Mikhalev A.S. Naksality i borba $s$ nimi pravitelstva Indii v pervom desyatiletii XXI veka: dis. ... kand. ist. nauk [The Naxalites and Indian Government's Fight with them in the First Decade of $21^{\text {th }}$ Century. Cand. hist. sci. diss.]. Volgograd, 2010. $260 \mathrm{p}$.

13. Serebryany A.Ya. I. P. Minaev kak istorik buddizma [I.P. Minaev as a Historian of Buddhism]. Istoricheskoe znanie $v$ sisteme politiki i kultury: sb. st. [The Historical Knowledge in the System of Policy and Culture]. Volgograd, Peremena Publ., 2005, pp. 78-83.

14. Serebryany A.Ya. Induism [Hinduism]. Volgograd, Peremena Publ., 2004. 80 p.

15. Serebryany A.Ya. Stanovlenie russkogo vostokovedeniya [The Rise of Russian Orientalism], Problemy novoy $i$ noveyshey istorii $i$ opyt sovremennosti [The Problems of Modern and Contemporary History and the Experience of Modernity]. Volgograd, Peremena Publ., 2009, pp. 180-188.

16. Kharinin A.I. «Neprikasaemye» kasty UttarPradesha [The Uttar Pradesh 'Untouchable' Casts]. Vestnik Volgogradskogo gosudarstvennogo universiteta. Seriya 4, Istoriya. Regionovedenie. 


\section{ХРОНИКА НАУЧНОЙ ЖИЗНИ}

Mezhdunarodnye otnosheniya [Science Journal of Volgograd State University. History. Area Studies. International Relations], 2015, no. 1 (31), pp. 32-41.

17. Kharinin A.I. «Neprikasaemye» etnokastovye soobschestva Indii: modernizatsiya sotsiokulturnyh traditsiy: dis. ... kand. ist. nauk [The 'Untouchable' Ethno-Casts Communities of India: Modernization of Sociocultural Traditions. Cand. hist. sci. diss.]. Volgograd, 2017.249p.
18. Kharinin A.I. Subyekt globalizatsii: ot transnatsionalnogo agenta $\mathrm{k}$ subyektivnomu faktoru planetarnoy integratsii [The Subject of Globalization: from Transnational Agent to Subjection Factor of Planet Integration]. Vestnik Volgogradskogo gosudarstvennogo universiteta. Seriya 7, Filosofiya, sotsiologiya i sotsialnye tekhnologii [Science Journal of Volgograd State University. Philosophy, sociology and Social Technologies], 2010, no. 2, pp. 142-147.

\section{Information About the Authors}

Vasiliy V. Tarakanov, Doctor of Sciences (Economics), Professor, Rector, Volgograd State University, Prosp. Universitetsky, 100, 400062 Volgograd, Russian Federation, rector@volsu.ru, http:// orcid.org/0000-0001-6971-0172

Irina K. Cheremushnikova, Doctor of Sciences (Philosophy), Professor, Department of History and Culture Studies, Volgograd State Medical University, Pavshikh Bortsov Sq., 1, 400131 Volgograd, Russian Federation, inhabitus@mail.ru, http://orcid.org/0000-0002-7211-0503

Aleksandr A. Kiselev, Candidate of Sciences (History), Consultant, Directorate of International and Regional Relations, Volgograd City Administration, Tsiolkovskogo St., 6, 400001 Volgograd, Russian Federation, aa-kiselev@volgadmin.ru,http://orcid.org/0000-0002-7687-3305

\section{Информация об авторах}

Василий Валерьевич Тараканов, доктор экономических наук, профессор, ректор, Волгоградский государственный университет, просп. Университетский, 100, 400062 г. Волгоград, Российская Федерация, rector@volsu.ru, http://orcid.org/0000-0001-6971-0172

Ирина Кабдрахимовна Черемушникова, доктор философских наук, профессор кафедры истории и культурологии, Волгоградский государственный медицинский университет, пл. Павших Борцов, 1, 400131 г. Волгоград, Российская Федерация, inhabitus@mail.ru, http://orcid.org/0000-00027211-0503

Александр Александрович Киселев, кандидат исторических наук, консультант управления зарубежных и региональных связей, Администрация Волгограда, ул. Циолковского, 6, 400001 г. Волгоград, Российская Федерация, aa-kiselev@volgadmin.ru, http://orcid.org/0000-0002-7687-3305 